\title{
Multi-Factorial Functional Analysis of the Patients with Reconstruction for Oral Carcinoma
}

\author{
Tsutomu Nomura, Susumu Shingaki, Tadaharu Kobayashi, Ichiro Suzuki, Chikara Saito \\ Division of Reconstructive Surgery for Oral and Maxillofacial Region, Department of Tissue Regeneration and \\ Reconstruction, Course for Oral Life Science, Graduate School of Medical and Dental Sciences, Niigata \\ University, Niigata, Japan \\ Email: t-nomura@bc5.so-net.ne.jp
}

Received 24 January 2015; accepted 4 March 2015; published 9 March 2015

Copyright (C) 2015 by authors and Scientific Research Publishing Inc.

This work is licensed under the Creative Commons Attribution International License (CC BY). http://creativecommons.org/licenses/by/4.0/

(c) (i) Open Access

\begin{abstract}
This paper is to evaluate postoperative function which has undergone reconstruction with vascularized or pedicled flaps for the treatment of oral carcinomas. The subjects consisted of 22 cases of 17 male and 5 female patients, and their mean age was 55 years. The sites of reconstruction were the tongue in 12 cases, mandible in 10 cases. The reconstruction was performed using deltopectoral (DP) flaps in 6 cases, pectoralis major musculo cutaneous (PMMC) flaps in 3 cases, DP flap + PMMC flap in one case, forearm (FA) flaps in 8 cases and peroneal (P) flaps with fibula in 4 cases. Postoperative masticatory, speech, swallowing functions and facial appearance were evaluated by Multi-factorial analysis. All functional results seem to be related to the type of resection. By multi-factorial analysis, the type of mandibular resection, flap area, and anterior resection were related to the masticatory or speech function in tongue resection. In mandibular resection, masticatory function was subjected to age; speech function was subjected to type of mandibular resection and plate reconstruction. The facial appearance was subjected to flap area. These results suggested that postoperative function was not related to only one factor, but using the classification of each defect site as one of the factor of multi-factorial analysis was useful.
\end{abstract}

\section{Keywords}

Oral Cancer, Postoperative Function, Reconstruction

\section{Introduction}

In spite of many advances in surgical technique in head and neck cancer, many patients suffer postoperative

How to cite this paper: Nomura, T., Shingaki, S., Kobayashi, T., Suzuki, I. and Saito, C. (2015) Multi-Factorial Functional Analysis of the Patients with Reconstruction for Oral Carcinoma. Open Journal of Stomatology, 5, 63-71.

http://dx.doi.org/10.4236/ojst.2015.53010 
dysfunction.

There are many factors influencing the postoperative functional status, such as primary site, $\mathrm{T}$ classification, flap type, irradiation and neck surgery. But, there is little information available concerning postoperative patient's function.

In the influencing factors, the size and extent of resection and type of flap of reconstruction used are considered to be important determinants of postoperative functional status in advanced oral carcinoma [1]-[7].

In this study, we investigated the postoperative function and the factors influencing function in patients who underwent reconstruction with vascularized or pedicled flaps for surgical defects.

\section{Patients and Methods}

From 23 patients who had undergone reconstructive surgery for oral cancer in our university hospital, one patient who had total necrosis of forearm (FA) flap was excluded. The subjects consisted of 17 male and 5 female patients who underwent reconstruction of defects resulting from treatment of carcinomas. Their mean age was 55 years. The sites of reconstruction were the tongue in 12 cases, mandible in 10 cases. The flaps for reconstruction were deltopectoral (DP) in 6 cases, pectoralis major musculocutaneous (PMMC) in 3 cases, DP and PMMC in one case, forearm (FA) in 8 cases and peroneal (P) with fibula in 4 cases (Table 1). The type of flap reconstruction for each patient was selected considering patient's general conditions. In mandible reconstruction, some patients had the plate reconstruction other than vascularized fibula flap for shortning the operation time.

For postoperative function, masticatory, speech, swallowing functions and facial appearance were evaluated. The evaluation was done by a grading system that was reported by our previous study (Table 2) [8] [9].

The masticatory function was evaluated by conducting interviews with patients, and classified into 4 grades from grade 1, able to eat a normal diet to grade 4, dependent on tube feeding. For postoperative speech function, the articulatory grade of the patients was classified by speech therapist into 5 grades from grade 1 , easy to understand and no problem in daily conversation to grade 5, unable to understand in conversation. Swallowing function was classified by interview into good, slightly disturbed and poor. Facial appearance was evaluated objectively by our team and classified as good, acceptable and poor. All evaluations were done in 6 months after operation.

The classification of extent of tumors is described in Figures 1-4 and Table 3.

To analyze the factor influencing the postoperative function, multivariable analysis was done.

For multivariable analysis, all independent factors which p value was less than 0.1 in the regression analysis were entered to multiple regression analysis. In this study, age, sex, TNM classification, flap size, free flap, irradiation, radical neck dissection, plate reconstruction, type of resection and residual tooth number were analyzed for masticatory, speech, swallowing function and facial appearance. Statistical analyses were performed by SPSS version 10.0 (SPSS, Inc.).

\section{Results}

\subsection{Function in Terms of Sites}

The detailed data of 22 patients entered in the functional analysis is described in Table 4. In the group of tongue resection, masticatory function was poor in patients with types 4 and 5 , and speech function was poor in patients

\begin{tabular}{cccc} 
Table 1. Reconstruction site and type of flaps. & \\
\hline & Tongue & Mandible & Total \\
\hline DP & 2 & 4 & 6 \\
PMMC & 2 & 1 & 3 \\
DP + PMMC & & 1 & 1 \\
FA & 7 & 1 & 8 \\
Peroneal & 1 & 3 & 4 \\
Total & 12 & 10 & 22 \\
\hline
\end{tabular}


Table 2. Gradings of masticatory, speech, and swallowing functions and facial appearance.

\begin{tabular}{|c|c|}
\hline \multicolumn{2}{|c|}{ A: Masticatory function } \\
\hline \multirow[t]{4}{*}{ Grade } & 1. able to eat normal diet \\
\hline & 2. able to eat soft diet \\
\hline & 3. able to eat liquid diet \\
\hline & 4. depend on tube-feeding \\
\hline \multicolumn{2}{|l|}{ B: Speech function } \\
\hline \multirow[t]{5}{*}{ Grade } & 1. easily understandable \\
\hline & 2. sometimes not understandable \\
\hline & 3. understandable if contents are previously informed \\
\hline & 4. sometimes understandable \\
\hline & 5. not understandable \\
\hline \multicolumn{2}{|c|}{ C: Swallowing function } \\
\hline \multirow[t]{3}{*}{ Grade } & 1. good \\
\hline & 2. slightly disturbed \\
\hline & 3. poor \\
\hline \multicolumn{2}{|c|}{ D: Facial appearance } \\
\hline \multirow[t]{3}{*}{ Grade } & 1. good \\
\hline & 2. acceptable \\
\hline & 3. poor \\
\hline
\end{tabular}

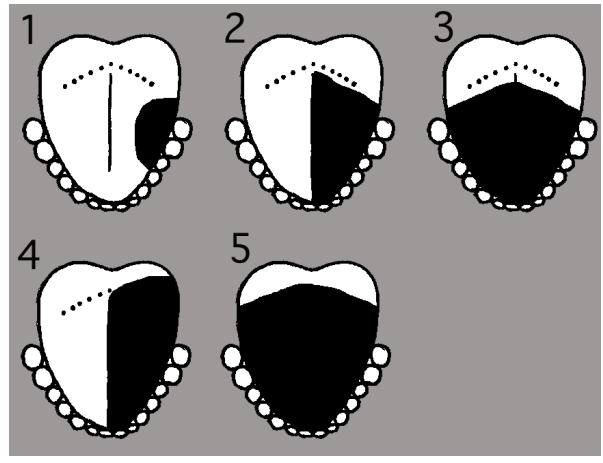

Figure 1. Classification of tongue resection.

with anterior tongue resection (types 3 and 5) (Table 5). Swallowing function and facial appearance were normal in all cases.

In the group of mandibular resection, masticatory function, speech function and facial appearance are seemed to be worse in advanced resection type (Table 6).

\subsection{Multiple Regression Analysis Study in Tongue and Mandible Resection}

In tongue resection, the $\mathrm{p}$ value of type of mandibular resection was 0.018 in masticatory function. And $\mathrm{p}$ value of flap area and anterior resection was 0.042 in speech function. When the larger flap was used, the speech function became better. And speech function was poor in patients with anterior tongue resection (Table 7). 


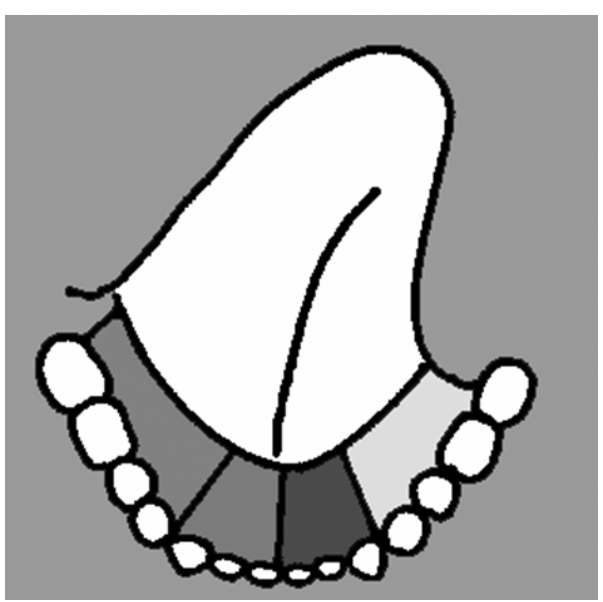

Figure 2. Classification of FOM resection.

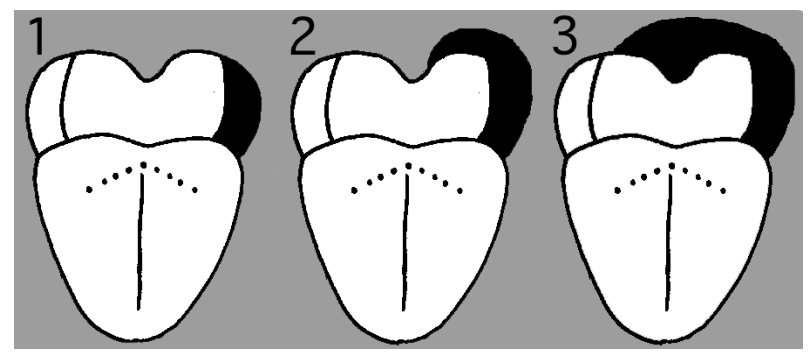

Figure 3. Classification of oropharynx resection.

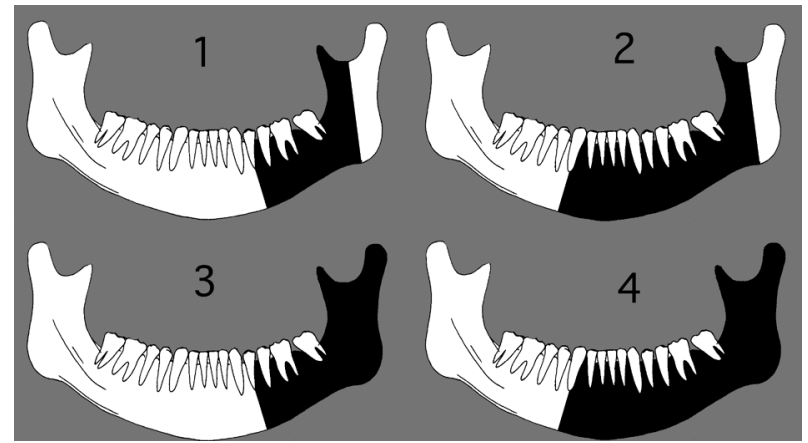

Figure 4. Classification of mandible resection.

In mandibular resection, age was an influencing factor $(p=0.038)$ in multiple regression analysis in masticatory function. $p$ value of plate reconstruction and type of mandibular resection were $0.008,0.012$ respectively in speech function. Facial appearance was influenced by flap area. When the larger flap was used, the function became better $(p=0.005)$.

\section{Discussion}

Reconstruction of the head and neck defects with flap is a routine procedure to minimize functional disturbance and facial deformity resulting from abrasive surgery.

There are many reports about various types of flap reconstruction for oral defects [1]-[20].

Talensnik et al. [16] said the free flap is better than PMMC and Vaughan et al. [17] compared free flaps with their previous study of pedicled flap and concluded that free flap had better outcome. Though, our data didn't show that the functional deference among flap types, the free flap is thought better than pedicled flap, because the free flap is pliable and can de-epitheliarize to pack into dead space [8]. 
Table 3. The classification of tumor resection.

\begin{tabular}{l} 
A. Tongue \\
1. partial resection of tongue \\
2. hemiglossectomy of mobile tongue \\
3. bilateral resection of anterior tongue \\
4. hemiglossectomy \\
5. total glossectomy \\
B. FOM \\
\hline 1. 1 part of FOM resection \\
2. 2 parts of FOM resection \\
3. 3 parts of FOM resection \\
4. 4 parts of FOM resection \\
C. Oropharynx \\
\hline 1. unilateral oropharyngeal resection \\
2. $1+$ unilateral soft palate resection \\
3. $1+$ bilateral soft palate resection \\
\hline D. Mandible \\
1. segmental mandibulectomy hemimandibulectomy \\
2. segmental mandibulectomy involving symphisis \\
\hline
\end{tabular}

Although posterior resection was mentioned to be a predictive factor for speech in tongue resection by Imai et al. [3], Pauloski et al. [12], and Schliephake et al. [15], our data showed that speech function was poor in patients with anterior tongue resection (type 3 and 5). This finding is almost same as Colangelo et al. [2] and Matsui et al. [20].

McConnel et al. [7] showed a relationship of swallowing function to extent of oral tongue and extent of tongue base resection, Colangelo et al. [2] and Zelefsky et al. [19] noted that T stage was a good predicting factor for speech and swallowing function. Our study had shown tumor site and flap area to be the predicting factor but no correlation with T stage. It is difficult to evaluate the accurate size of defects, because of complicated structures in the posterior tongue area, thus we have to consider the tumor site and flap size as well as the tumor size to evaluate postoperative function. Colangelo et al. [2] also investigated the effect of irradiation to functional outcome, and he found no effects.

Our data didn't show the irradiation influenced the postoperative function neither.

In terms of masticatory function in tongue resection, only the type of mandibular resection was related to the function. Combination of the type of resection, for example type 2 tongue resection + type 3 mandibular resection, was thought to be a predictive factor.

In mandible region, $\mathrm{T}$ and stage classification weren't used. Because all cases in this study had $\mathrm{T} 4$ and stage 4, we were unable to compare the $\mathrm{T}$ and stage classification. The difference in volume of flap area was noted in facial appearance. This result means that the larger flap had good facial appearance. In speech function, type of mandibular resection and plate reconstruction were affected function.

In masticatory function, the age is related to function. This result means that old patients with many systemic disease had more minimal surgery as plate reconstruction rather than bony reconstruction. This should be a reason for the age was related to the function. 
Table 4. Clinical findings of patients $(n=22)$.

\begin{tabular}{|c|c|c|c|c|c|c|c|c|c|c|c|c|c|c|c|c|c|c|c|c|c|c|c|c|}
\hline \multirow{2}{*}{\multicolumn{3}{|c|}{ Case Age Sex }} & \multirow{2}{*}{ Site } & \multirow{2}{*}{\multicolumn{2}{|c|}{ Diag. $\mathrm{T}$}} & \multirow{2}{*}{$\mathrm{N}$} & \multirow{2}{*}{ Stage } & \multirow{2}{*}{ Area } & \multirow{2}{*}{$\mathrm{Rx}$} & \multirow{2}{*}{ Reconst. } & \multirow[b]{2}{*}{ Plate } & \multirow{2}{*}{\multicolumn{2}{|c|}{ Timing RND }} & \multicolumn{4}{|c|}{ Type of resection } & \multicolumn{5}{|c|}{ Function } & \multirow[b]{2}{*}{ Face } & \multirow{2}{*}{ Tooth } \\
\hline & & & & & & & & & & & & & & tongu & ant & nand. & FOM & Oro. & Max. & Mast. & & Sw. & & \\
\hline 1 & 43 & M & mand. & SCC & 42 & $2 b$ & 4 & 49 & 50.0 & DP & & 0 & 1 & & & 2 & 2 & 1 & & 2 & 1 & 1 & 3 & 22 \\
\hline 2 & 53 & M & mand. & SCC & 4 & 1 & 4 & 48 & 50.0 & DP & 1 & 0 & 1 & & & 2 & 3 & 1 & & 2 & 2 & 1 & 3 & 13 \\
\hline 3 & 56 & M & mand. & SCC & 4 & 1 & 4 & 80 & 74.4 & DP & 1 & 0 & 1 & & & 3 & 2 & 2 & + & 2 & 3 & 1 & 2 & 19 \\
\hline 4 & 49 & $\mathrm{M}$ & mand. & SCC & 4 & 1 & 4 & 100 & 50.0 & $\begin{array}{c}\text { DP + } \\
\text { PMMC }\end{array}$ & & 0 & 1 & & & 2 & 2 & 0 & & 2 & 1 & 1 & 2 & 21 \\
\hline 5 & 36 & M & mand. & SCC & & $2 b$ & 4 & 36 & 50.0 & FA & & 0 & 1 & 4 & - & 4 & 2 & 2 & & 2 & 2 & 1 & 3 & 19 \\
\hline 6 & 36 & M & mand. & SCC & 42 & $2 b$ & 4 & 80 & 50.0 & peroneal & & 1 & 1 & 4 & - & 4 & 2 & 2 & & 1 & 2 & 1 & 2 & 19 \\
\hline 7 & 57 & $\mathrm{~F}$ & mand. & SCC & 4 & 0 & 4 & 64 & 0.0 & peroneal & & 0 & 0 & & & 2 & 1 & 0 & & 2 & 1 & 1 & 2 & 13 \\
\hline 8 & 59 & M & mand. & SCC & 4 & 1 & 4 & 48 & 42.0 & PMMC & & 0 & 1 & & & 4 & 2 & 0 & & 2 & 2 & 1 & 3 & 3 \\
\hline 9 & 56 & M & mand. & SCC & 42 & $2 b$ & 4 & 64 & 60.0 & DP & & 0 & 1 & & & 3 & 2 & 1 & & 2 & 2 & 1 & 3 & 17 \\
\hline 10 & 37 & M & mand. & SCC & 4 & 0 & 4 & 72 & 63.8 & peroneal & & 0 & 1 & & & 2 & 2 & 0 & & 1 & 1 & 1 & 2 & 18 \\
\hline 11 & 50 & $\mathrm{~F}$ & Tongue & SCC & 2 & 0 & 2 & 56 & 18.0 & DP & & 0 & 1 & 2 & - & & 2 & & & 1 & 1 & 1 & 1 & 28 \\
\hline 12 & 68 & M & Tongue & SCC & 42 & $2 c$ & 4 & 48 & 0.0 & DP & & 0 & 1 & 5 & + & & 2 & 1 & & 2 & 3 & 1 & 1 & 22 \\
\hline 13 & 68 & $\mathrm{~F}$ & Tongue & SCC & 2 & 1 & 3 & 24 & 0.0 & FA & & 0 & 0 & 4 & - & & 2 & & & 1 & 2 & 1 & 1 & 28 \\
\hline 14 & 59 & M & Tongue & SCC & 2 & 0 & 2 & 28 & 0.0 & FA & & 0 & 0 & 4 & - & & 2 & 1 & & 1 & 3 & 1 & 1 & 26 \\
\hline 15 & 67 & $\mathrm{M}$ & Tongue & SCC & 2 & 0 & 2 & 25 & 50.0 & FA & & 0 & 1 & 4 & - & & 2 & 1 & & 2 & 2 & 1 & 1 & 2 \\
\hline 16 & 58 & $\mathrm{~F}$ & Tongue & SCC & 32 & $2 b$ & 4 & 48 & 50.0 & FA & & 0 & 1 & 5 & + & & 2 & 1 & & 1 & 2 & 1 & 1 & 5 \\
\hline 17 & 55 & $\mathrm{M}$ & Tongue & SCC & 2 & 1 & 3 & 30 & 0.0 & FA & & 0 & 1 & 3 & + & & 3 & & & 1 & 3 & 1 & 1 & 21 \\
\hline 18 & 61 & $\mathrm{~F}$ & Tongue & SCC & 3 & 0 & 3 & 25 & 0.0 & FA & & 0 & 0 & 5 & + & & 2 & 1 & & 1 & 2 & 1 & 1 & 28 \\
\hline 19 & 68 & M & Tongue & SCC & 4 & 1 & 4 & 36 & 0.0 & FA & & 0 & 1 & 5 & + & & 2 & 1 & & 2 & 3 & 1 & 1 & 27 \\
\hline 20 & 48 & $\mathrm{M}$ & Tongue & SCC & 32 & $2 c$ & 4 & 84 & 50.0 & peroneal & & 0 & 1 & 4 & - & 1 & 2 & 1 & & 3 & 1 & 1 & 1 & 26 \\
\hline 21 & 60 & M & Tongue & SCC & 3 & 1 & 3 & 64 & 70.0 & PMMC & & 0 & 1 & 4 & - & & 2 & & & 1 & 1 & 1 & 1 & 13 \\
\hline 22 & 58 & $\mathrm{M}$ & Tongue & SCC & 3 & 1 & 3 & 40 & 99.0 & PMMC & & 0 & 1 & 3 & + & & 2 & & & 1 & 3 & 1 & 1 & 20 \\
\hline
\end{tabular}

mand.: mandible; SSC: squamous cell carcinoma; Area: flap area; 0: primary; 1: secondary; ant: anterior resction of tongue; Max.: maxilla; Mast.: mastication; Sp.: Speech; Sw.: swallowing.

Table 5. Function in patients with tongue resection $(n=12)$.

\begin{tabular}{|c|c|c|c|c|}
\hline \multicolumn{5}{|c|}{ Type of resection (1-5) } \\
\hline & 2 & 3 & 4 & 5 \\
\hline \multicolumn{5}{|c|}{ Masticatory function (1-4) } \\
\hline 1 & 1 & 2 & 3 & 2 \\
\hline 2 & & & 1 & 2 \\
\hline 3 & & & 1 & \\
\hline \multicolumn{5}{|c|}{ Speech function (1-5) } \\
\hline 1 & 1 & & 2 & \\
\hline 2 & & & 2 & 1 \\
\hline 3 & & 2 & 1 & 3 \\
\hline
\end{tabular}


Table 6. Function in patients with mandibular resection $(\mathrm{n}=10)$.

\begin{tabular}{llll}
\hline & Type of resection & \\
\hline 2 & 3 & 4
\end{tabular}

Masticatory function (1-4)

$\begin{array}{llll}1 & 1 & & 1 \\ 2 & 4 & 2 & 4\end{array}$

Speech function (1-5)

$\begin{array}{llll}1 & 4 & & \\ 2 & 1 & 1 & 3 \\ 3 & & 1 & \end{array}$

Face appearance (1-3)

$\begin{array}{llll}2 & 3 & 1 & 1 \\ 3 & 2 & 1 & 2\end{array}$

Table 7. Multiple regression analysis of function after resection.

\begin{tabular}{|c|c|c|c|c|}
\hline \multicolumn{5}{|c|}{ A. Tongue } \\
\hline & $\mathrm{R}^{2}$ & $P$ value & SC & VIF \\
\hline Mastication & 0.753 & & & \\
\hline Sex & & 0.266 & 0.239 & 1.111 \\
\hline $\mathrm{T}$ & & 0.142 & 0.341 & 1.209 \\
\hline Flap area & & 0.380 & -0.265 & 2.262 \\
\hline Type of mand & & 0.018 & 0.846 & 2.128 \\
\hline Speech & 0.624 & & & \\
\hline Flap area & & 0.042 & -0.499 & 1.068 \\
\hline Anterior & & 0.042 & 0.499 & 1.068 \\
\hline \multicolumn{5}{|c|}{ B: Mandible } \\
\hline & $\mathrm{R}^{2}$ & $P$ value & SC & VIF \\
\hline Mastication & 0.433 & & & \\
\hline Age & & 0.038 & 0.658 & 1.00 \\
\hline Speech & 0.934 & & & \\
\hline $\mathrm{Rx}$ & & 0.934 & 0.129 & 1.445 \\
\hline Plate & & 0.008 & 0.654 & 1.816 \\
\hline Type of mand & & 0.012 & 0.635 & 2.051 \\
\hline Type of Oro & & 0.621 & 0.085 & 1.959 \\
\hline Face & 0.785 & & & \\
\hline $\mathrm{N}$ & & 0.096 & 0.348 & 1.070 \\
\hline Flap area & & 0.005 & -0.731 & 1.070 \\
\hline
\end{tabular}

SC: Standardized Coefficients; VIF: Variance inflation factor; mand.: mandible; oro.: oropharynx. 
About the classification of type of resection for oral cancer, Jacobson et al. [5] used 5 categories and Yamashita et al. [18] used 8 categories for oral and oropharyngeal defects. And Imai et al. [3] made a classification by combination of 6 type of tongue resection and 3 types of FOM resection. We have been using original criteria as seen in Table 4 and Figures 1-4, for many years. This time, we proposed the combinated expression of each defect score, and the usage of multivariate analysis. In our classification, type of mandibular resection correlated with masticatory function in tongue resection and speech function in mandibular resection. And anterior resection of tongue had worse speech function.

Although this study was performed in only small samples, post-operative functions were suggested to have relation with type of defects and type of reconstructions. Using the classification of each defect site as one of the factor of multi-factorial analysis is suggested to be useful.

\section{Conclusion}

All functional results seem to be related to the type of resection. These results suggested that postoperative function was not related to only one factor, but using the classification of each defect site as one of the factor of multi-factorial analysis was useful.

\section{Funding}

None.

\section{Competing Interests}

None declared.

\section{Ethical Approval}

Not required.

\section{References}

[1] Cheema, M.A. (1993) Pectoralis Major Myocutaneous Flap for Reconstruction of Defects Following Resections in Head and Neck Area. Journal of Pakistan Medical Association, 43, 73-76.

[2] Colangelo, L.A., Logemann, J.A., Pauloski, B.R., Pelzer, H.J. and Rademaker, A.W. (1996) T Stage and Functional Outcome in Oral and Oropharyngeal Cancer Patients. Head and Neck, 18, 259-268. http://dx.doi.org/10.1002/(SICI)1097-0347(199605/06)18:3<259::AID-HED8>3.0.CO;2-Z

[3] Imai, S., Mich, K., Yamashita, Y., Yoshida, H., Michiwaki, Y., Ohno, K. and Suzuki, N. (1988) Speech Intelligibility after Resection of the Tongue and Floor of the Mouth. Journal of Oral and Maxillofacial Surgery, Medicine, and Pathology, 34, 34-53.

[4] Ioannides, C., Fossion, E. and Vrielinck, L. (1991) Pectoralis Major Myocutaneous Island Flap for Cervicofacial Reconstruction: A 9-Year Experience. Acta Chirurgica Belgica, 91, 211-218.

[5] Jacobson, M.C., Franssen, E., Fliss, D.M., Birt, B.D. and Gilbert, R.W. (1995) Free Forearm Flap in Oral Reconstruction. Archives of Otolaryngology—Head and Neck Surgery, 121, 959-964. http://dx.doi.org/10.1001/archotol.1995.01890090005001

[6] Kingdom, T.T. and Singer, M.I. (1996) Enhanced Reliability and Renewed Applications of the Deltopectoral Flap in Head and Neck Recostruction. The Laryngoscope, 106, 1230-1233.

http://dx.doi.org/10.1097/00005537-199610000-00011

[7] McConnel, F.M., Logemann, J.A., Randemaker, A.W., et al. (1994) Surgical Variables Affecting Postoperative Swallowing Efficiency in Oral Cancer Patients: A Pilot Study. The Laryngoscope, 104, 87-90. http://dx.doi.org/10.1288/00005537-199401000-00015

[8] Nomura, T., Shibata, M., Suzuki, I., Kohno, M., Shingaki, S. and Nakajima, T. (1997) Clinical Evaluation of Vascularized Fibula Grafts for Mandibular Reconstruction in 6 Cases. Asian Journal of Oral and Maxillofacial Surgery, 9, 31-38.

[9] Nomura, T., Suzuki, I., Kohno, M., Shingaki, S. and Nakajima, T. (1998) Reconstruction of the Mandible with Bone Grafts and Metal Plates: Analysis of 42 Cases. Asian Journal of Oral and Maxillofacial Surgery, 10, 7-15.

[10] O’Brien, C.J., Lee, K.K., Stern, H.S., Traynor, S.J., Bron, L., Tew, P.J. and Haghighi, K.S. (1998) Evaluation of 250 
Free-Flap Reconstruction after Resection of Tumors of the Head and Neck. Australian and New Zealand Journal of Surgery, 68, 698-701. http://dx.doi.org/10.1111/j.1445-2197.1998.tb04654.x

[11] Olstad, O.A., Skjelbred, P. and Lyberg, T. (1996) Reconstruction of the Jaw and Oral Cavity with Free Vascularized Grafts. Tidsskrift for den Norske Legeforening, 116, 2431-2435.

[12] Pauloski, B.R., Logemann, J.A., Colangelo, L.A., Rademaker, A.W., McConnel, F.M.S., Heiser, M.A., et al. (1998) Surgical Variables Affecting Speech in Treated Patients with Oral and Oropharyngeal Cancer. Laryngoscope, 108, 908-916. http://dx.doi.org/10.1097/00005537-199806000-00022

[13] Pogrel, M.A., Podlesh, S., Anthony, J.P. and Alexander, J. (1997) A Comparison of Vascularized and Nonvascularized Bone Grafts for Reconstruction of Mandibular Continuity Defects. Journal of Oral and Maxillofacial Surgery, 55, 1200-1206. http://dx.doi.org/10.1016/S0278-2391(97)90165-8

[14] Schliephake, H., Schmelzeisen, R., Schonweiler, R., Schneller, T. and Altenbernd, C. (1998) Speech, Deglutition and Life Quality after Intraoral Tumor Resection. International Journal of Oral and Maxillofacial Surgery, 27, 99-105. http://dx.doi.org/10.1016/S0901-5027(98)80304-4

[15] Shpitzer, T., Neilgan, P.C., Gulllane, P.J., Freeman, J.E., Boyd, B.J., Rotstein, L.E., Brown, D.H., Irish, J.C. and Gur, E. (1997) Oromandibular Reconstruction with the Fibular Free Flap: Analysis of 50 Consecutive Flaps. JAMA Otolaryngology-Head and Neck Surgery, 123, 939-944. http://dx.doi.org/10.1001/archotol.1997.01900090051007

[16] Talensnik, A., Markowitz, B., Calcaterra, T., Ahn, C. and Shaw, W. (1996) Cost and Outcome of Osteocutaneous Free Tissue Transfer versus Pedicled Soft-Tissue Reconstruction for Composite Mandibular Defects. Plastic \& Reconstructive Surgery, 97, 1167-1178. http://dx.doi.org/10.1097/00006534-199605000-00011

[17] Vaughan, E.D., Bainton, R. and Martin, I.C. (1992) Improvements in Morbidity of Mouth Cancer Using Microvascular Free Flap Reconstructions. Journal of Cranio-Maxillofacial Surgery, 20, 132-134. http://dx.doi.org/10.1016/S1010-5182(05)80095-2

[18] Yamashita, Y., Ohno, K., Imai, S., Matui, Y., Takahashi, K., Michiwaki, Y. and Michi, K. (1995) Assessment of Mastication, Deglutition and Ingestion of Oral Cancer Patients Reconstructed with Free Radial Forearm Flap. Journal of the Japanese Stomatological Society, 44, 55-65.

[19] Zelefsky, M.J., Gaynor, J., Kraus, D., Strong, E.W., Stah, J.P. and Harrison, L.B. (1996) Long-Term Subjective Functional Outcome of Surgery Plus Postoperative Radiotherapy for Advanced Stage Oral Cavity and Oropharyngeal Carcinoma. American Journal of Surgery, 171, 258-261. http://dx.doi.org/10.1016/S0002-9610(97)89563-3

[20] Matsui, Y., Ohno, K., Yamashita, Y. and Takahashi, K. (2007) Factors Influencing Postoperative Speech Function of Tongue Cancer Patients Following Reconstruction with Fasciocutaneous/Myocutaneous Flaps-A Multicenter Study. International Journal of Oral and Maxillofacial Surgery, 36, 601-609. http://dx.doi.org/10.1016/j.ijom.2007.01.014 